\title{
B5 Eficiência da purificação, concentração e formulação dos soros hiperimunes do Instituto Vital Brazil, segundo a dinâmica dos níveis de imunoglobulinas
}

Aniesse Silva Aguiar ${ }^{1}$, Michelle Pacheco de Lima ${ }^{1}$, Moacir de Souza Silva ${ }^{1}$, Camila Braz Pereira da Costa ${ }^{1}$, Jorge Luiz Coelho Mattos ${ }^{1}$

${ }^{1}$ Instituto Vital Brazil

Introdução: Os soros hiperimunes são imunoglobulinas purificadas ( $\lg G$ ), fracionadas em $F(a b) 2$ (porção bivalente, com dois sítios de agregação para o antígeno) e concentradas a partir do plasma de equídeos hiperimunizados. O processo envolve diversas fases e variadas condições físico-químicas cujas manipulações podem ser determinantes na facilitação de perdas de rendimento, conforme a labilidade da imunoglobulina trabalhada.

Objetivo: O estudo objetivou avaliar a eficiência dos processos de produção do Instituto Vital Brazil (IVB), correlacionando às frações dos anticorpos quantificados proteicamente, com sua capacidade neutralizante "in vivo".

Metodologia: Foram analisadas 61 amostras de soros hiperimunes. As proteínas dos soros foram determinadas pelo método do Biureto e as potências obtidas pela técnica de soroneutralização (utilizando os diferentes antígenos nas doses padrões de desafio) em camundongos albinos suíços. O grau de pureza foi avaliado pelo perfil eletroforético dos soros. Assim, foram feitas identificações das proteínas presentes em cada fase do processo produtivo através da eletroforese em filme de agarose geral com o sistema tampão descontínuo, integrados em scanner modelo CanoScan LiDE 25, e da eletroforese de gel de poliacrilamida (EGPA-SDS).

Resultados: Nas avaliações de proteínas totais nas ampolas encontramos um valor médio de $3,5 \mathrm{~g} \%$. Nos perfis (EGPA-SDS) dos plasmas comparados com as amostras dos soros já concentrados e acabados, observamos que na grande maioria, a faixa das imunoglobulinas íntegras no plasma (de 150 a $180 \mathrm{kDa}$ ) passaram a figurar de forma reduzida nos soros (com hidrólise da IgG para $F(a b ') 2$ ), aparecendo na faixa de 100 a $130 \mathrm{kDa}$. Igualmente observamos nas amostras de plasma a presença significante de traços de albumina (peso molecular de $66 \mathrm{kDa}$ ) que praticamente desaparecem nos soros que também passaram pelo fracionamento (digestão péptica), figurando entretanto numa faixa de peso inferior, com peso aproximado de $20 \mathrm{kDa}$, resultante da proteólise da albumina. Destacamos os soros antirrábicos e antiescorpiônicos como os mais críticos quanto à eficiência do processo de produção quando comparados aos antiofídicos e antitetânicos. Os soros ampolados possuem uma concentração média de $71 \%$ de proteínas correspondentes às 
Imunoglobulinas, variando segundo o tipo de soro. Os antibotrópicos são os de maior rendimento, chegando o antibotrópico-Laquético à média de $80 \%$, ao contrário dos soros Antirrábico e Anticrotálico com médias de $64-66 \%$.

Conclusão: Pelas análises eletroforéticas, concluímos que o teor de

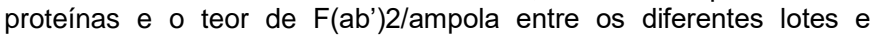
diferentes tipos de soros variam consideravelmente. Em decorrência, sugerimos a inclusão da análise do perfil eletroforético como prova de rotina do controle de qualidade para acompanhamento do processo produtivo, no sentido de revelar a eficiência da remoção das proteínas inespecíficas às $F(a b) 2$. Cabe destacar que os soros do IVB sempre tiveram a potência neutralizante acima do exigido, e os seus teores de proteína total muito abaixo dos valores máximos de referência da Farmacopéia Brasileira.

Palavras-Chave: Imunobiológicos, Biofármacos, Anticorpos Heterólogos 